\title{
Study on the Effect and Mechanism of Aerodynamic Measures for the Vortex-Induced Vibration of Separate Pairs of Box Girders in Cable-Stayed Bridges
}

\author{
Han Xin $\mathrm{He}^{1}$ and Jia Wu $\mathrm{Li}^{2}$ \\ ${ }^{1}$ School of Civil Engineering, Xi'an University of Architecture and Technology, Xian, Shaanxi 710055, China \\ ${ }^{2}$ School of Highway, Chang'an University, Xi'an, Shaanxi 710064, China \\ Correspondence should be addressed to Han Xin He; hehanxin@126.com
}

Received 14 October 2014; Revised 25 December 2014; Accepted 22 January 2015

Academic Editor: Sakdirat Kaewunruen

Copyright (c) 2015 H. X. He and J. W. Li. This is an open access article distributed under the Creative Commons Attribution License, which permits unrestricted use, distribution, and reproduction in any medium, provided the original work is properly cited.

\begin{abstract}
Although not always resulting in catastrophic failures, vortex-induced vibration (VIV) response can seriously impact the fatigue life and functionality of bridges, especially for separate pairs of box girders in cable-stayed bridges. This study investigates the effects of three aerodynamic measures: grating, inclined web plate, and the baffles on separated box girders in the cable-stayed bridges. The experimental result indicates that the grating of different opening ratios can control the vortex-induced vibration effectively, and the optimized grating opening ratio set in this paper is $40 \%$. Increasing the angle of inclined web plate has a great control on mitigation of the vortex-induced vibration. However, there is an optimum angle where the amplitude of vortex-induced vibration is the smallest at low wind speed. The amplitude of vortex-induced vibration becomes larger with the increase of the web inclined angle that exceeds the optimum angle. Comparatively, the baffles installed on both sides of the inclined webs are more effective to restrain the vortex-induced resonance. The Computational Fluent Dynamics (CFD) software is utilized to investigate the mechanism of the experimental results.
\end{abstract}

\section{Introduction}

The vortex-induced vibration (VIV) is a typical windinduced vibration, especially for long-span bridges. Due to nonlinear fluid structure interactions, the vortex-induced vibration (VIV) exhibits the limit cycle oscillations (LCOs). Although not always resulting in catastrophic failures, VIV response can seriously impact the fatigue life and functionality of buildings. It should be noted that the focus of most studies in the past was on the VIV of circular cylinders [1-11]; however, the VIV of bridge decks, as a typical bluff body of structural works, exhibits substantially different flow features from circular cylinders. In order to study the characteristics of VIV of bridge decks, many researchers have made a lot of works from several aspects. Komatsu and Kobayashi [12] carried out a series of experiments on various cross sections with various aspect ratios, so they noted that Karman vortex street (generated from the trailing edge) and motion-induced vortex (generated from the leading edge) were the two main sources of VIV of bluff prismatic cylinders. Shiraishi and Matsumoto [13] investigated five simplified bridge deck cross sections with various aspect ratios to guide the deck optimization towards VIV response reduction. The results indicated that bridge decks with a longer rear body are more effective in mitigating VIV. Matsumoto et al. [14] investigated the interaction between Karman and motion-induced vortices for a rectangular cylinder with an aspect ratio of $4: 1$ and a hexagonal box girder with/without handrails; the experimental results indicated that the VIV of both models was essentially excited by the motion-induced vortices which were mitigated by the presence of Karman vortices. Larose et al. [15] investigated the Reynolds number effect on the VIV of Stonecutters Bridge. It appeared that the bridge deck appendages (e.g., longitudinal guide vanes and maintenance 
gantry rails) were less efficient in mitigating VIV response at low Reynolds number as compared to high Reynolds number. Owen et al. [16] monitored the Kessock Bridge with an "open cross section" and pointed out that it needed a certain time to build up a large amplitude response of VIV after the corresponding vortex shedding occurred. To decrease the intense VIV response observed on the RioNiterói Bridge with a steel twin-box bridge deck, Ronaldo and Michèle [17] designed passive and active control devices which significantly decreased or ceased the VIV from a much larger intensity observed on site. With the burgeoning growth in computational capability, CFD is becoming a powerful tool for the analysis of wind-induced effects on the structures. Fujiwara et al. [18] investigated the VIV of bridge decks with three types of elastically mounted edge-beam cross sections in 2D domain through direct integration of Navier-Stokes equations. Nomura [19] investigated the VIV of a Tacomalike bridge deck (thin-H section with an aspect ratio of 5) in 2D domain based on the finite element method using the arbitrary Lagrangian-Eulerian formulation.

Recently, Zhang et al. [20] investigated the VIV of Xihoumen Bridge deck (twin-box) with various scaled models. The experimental results indicated that in the case of low Reynolds number, the "lock-in" emerges at higher and widerrange of damping ratio with larger amplitude and wider wind velocity range compared to high Reynolds number cases. $\mathrm{Li}$ et al. [21, 22] studied the VIV of a suspension bridge with a twin-box girder and with a $1650 \mathrm{~m}$ center span. It was identified that the structural motion increased the vortex shedding intensity; the vortex shedding in the "lock-in" stage not only occurred in the gap between the two bridge decks and at the tail end of the downstream deck section as in the early stage of VIV, but also happened at the tail end of the upstream deck section around the entire lower surface of the downstream deck. Marra et al. [23] made use of Van der Pol-type equation to simulate the VIV of bridge decks. It was observed that the equation is coherent with the physical characteristics of the phenomenon. Patil et al. [24] studied the balance of the damping measures and the resulting cost by formulating the problem as multiobjective optimization problem. Seo et al. [25] discussed the interference effect on VIV in a parallel twin cable-stayed bridge. The result indicated that several modifications of aerodynamic additives were not effective in reducing the VIV, but an increase in structural damping effectively mitigated the vibration. Zhu et al. [26] carried out a new improved empirical nonlinear model of vortex-induced force which is proved to be more suitable to the concerned flat closed-box bridge decks than Scanlan's empirical nonlinear model. Kim et al. [27] researched the deep interference of VIV between two parallel cable-stayed bridges with respect to the mutual motion of both downstream and upstream decks by field monitoring. It is observed that damping force and wind direction have great influence on the interactive VIV. Morgenthal et al. [28] carried out a pseudo-threedimensional extension of the vortex practical method.

In this paper, we discussed the effects of different aerodynamic measures on the VIV of separate pairs of box girders through a wind tunnel test and tried to explain their control mechanism by using the Computational Fluent Dynamics (CFD) technology. Compared to the closed box girders, the flutter stability of the separate pair of box girders has been improved significantly, which, however, is compensated by high VIV possibility $[29,30]$. In order to restrain the VIV of the bridge with separate pairs of box girders, it is important to choose an appropriate aerodynamic configuration. However, up to now, the corresponding reports based on the aerodynamic research of separate box girders are relatively few.

\section{Engineering Background}

Hongkong-Zhuhai-Macao River-Sea Ship Canal Bridge is a three-tower cable-stayed bridge and is $129+258+258+129 \mathrm{~m}$ in span (774 $\mathrm{m}$ totally). The bridge uses single column type towers. The height of any of its towers is $96 \mathrm{~m}$. The overall width of the girder is $38.8 \mathrm{~m}$. The height of the portion with a center line is $4 \mathrm{~m}$. The standard cross section of the girder is shown in Figure 1. The primary vibration modes of the bridge are shown in Table 1.

\section{Experimental Study}

3.1. General. In order to study the characteristics of the VIV, the vibration measurement test of segmental models is conducted in the CA-1 atmospheric boundary layer wind tunnel of Changan University, to determine the best VIVresistant measures of the bridge. The test setups include $\alpha$ rotary mechanism, laser acceleration sensors, laser displacement sensors, DAWON DAQ system and computer for data acquisition and processing.

3.1.1. Settings. The spring suspended model with a scale ratio of 1:45 is made by using aluminum alloy as spine foam filler and epoxy resin board as coat. Mechanical springs are connected with a $\alpha$ rotary mechanism, which is used to adjust the wind attack angle. Figure 2 shows the segment vibration measurement model suspended in the wind tunnel. Similarity factors listed in Table 2 are followed in the test.

As shown in Figure 3, two laser displacement sensors are arranged at the end of the beam equidistant from the center. The values of vertical bending displacement and torsion response can be obtained through algebraic sum and algebraic difference operations for the measurements taken by laser displacement sensors. Two acceleration sensors are arranged on the rigid arms equidistant from the center in order to verify the data.

3.1.2. Test Conditions. The VIV generally occurs at low wind speed. In this test, the wind speed ranges from $5 \mathrm{~m} / \mathrm{s}$ to $35 \mathrm{~m} / \mathrm{s}$. The wind attack angles are $-3^{\circ}, 0^{\circ}$, and $+3^{\circ}$, respectively. Damping ratios of vertical bending and torsion are $0.21 \%$ and $0.23 \%$, respectively. Considering little influence of turbulent on the amplitude of VIV, the test is conducted in uniform flow conservatively.

3.2. Wind Tunnel Test. It can be seen from the result of the wind tunnel test that there are two VIV parts for the deck. The first one is at the wind speed from $8.37 \mathrm{~m} / \mathrm{s}$ to 


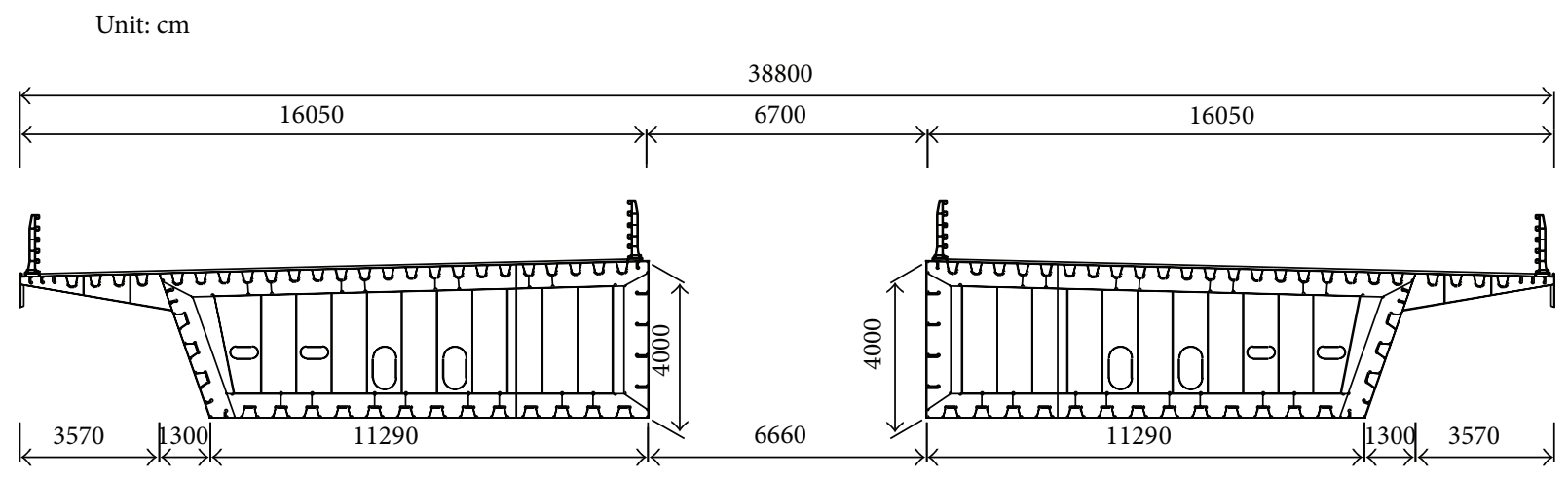

FIgURE 1: Standard cross section of the girder.

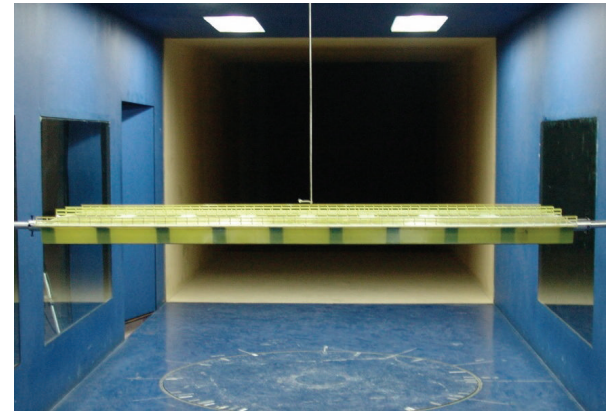

FIGURE 2: Segment vibration measurement model.

TABLE 1: Natural vibration frequencies and vibration modes description of primary vibration modes of the bridge.

\begin{tabular}{|c|c|c|}
\hline $\begin{array}{l}\text { Vibration } \\
\text { mode } \\
\text { number }\end{array}$ & $\begin{array}{l}\text { Frequency } \\
\qquad(\mathrm{Hz})\end{array}$ & Description of vibration modes \\
\hline 1 & 0.3435 & $\begin{array}{l}\text { Antisymmetrical vertical bending of } \\
\text { main girder }\end{array}$ \\
\hline 2 & 0.4759 & $\begin{array}{l}\text { Symmetrical vertical bending of main } \\
\text { girder }\end{array}$ \\
\hline 4 & 0.7529 & $\begin{array}{l}\text { Antisymmetrical side bending of main } \\
\text { girder }\end{array}$ \\
\hline 6 & 0.8719 & Side tower equidirectional side vibration \\
\hline 7 & 0.8840 & Reverse side vibration of side tower \\
\hline 8 & 0.9119 & $\begin{array}{l}\text { Symmetrical side bending of main } \\
\text { girder }+ \text { reverse side vibration of side } \\
\text { tower }\end{array}$ \\
\hline 10 & 0.9423 & Symmetrical torsion of main girder \\
\hline 11 & 0.9449 & Antisymmetrical torsion of main girder \\
\hline 13 & 0.9795 & Side vibration of middle tower \\
\hline
\end{tabular}

$11.47 \mathrm{~m} / \mathrm{s}$, with the peak amplitude of $129.955 \mathrm{~mm}$ observed at the wind attack angles of $0^{\circ}$ and $3^{\circ}$; the other is at the wind speed from $18.6 \mathrm{~m} / \mathrm{s}$ to $31.31 \mathrm{~m} / \mathrm{s}$, with the peak amplitude of $205.960 \mathrm{~mm}$ observed at the wind attack angle of $-3^{\circ}$. The first one is vertical bending VIV, and the other is torsional VIV. The characteristics of the original girder VIV are shown in
Table 3. In order to mitigate the VIV, several measures have been studied.

3.2.1. Grating. As shown in Figure 4, grating is attached in the central slotting of the girders. $m / M$ is defined as the grating ratio, where $M$ is the outline width of the grating and $m$ is the cavity width of the grating. The varying ratios can be obtained by adjusting the value of $m$.

In order to get an optimum opening ratio, this study uses five opening ratios, namely, $0 \%, 20 \%, 40 \%, 60 \%$, and $80 \%$, by comparing their VIV amplitude with that of the proposed deck.

3.2.2. Angle of Inclined Web. Web plate inclined angle is defined as the angle (obtuse angle) between the inclined web and the bottom, as shown in Figure 5. This study focuses on the effect of web plate inclined angle on the VIV by setting the angle as $119^{\circ}, 129^{\circ}$, and $139^{\circ}$, respectively.

3.2.3. Baffles. Baffles are set on both sides of the inclined webs and in central slotting position, respectively. In the former condition, baffles are set paralleled to the inclined webs and bottom plate of the model. The distance between the baffle and the model is $15 \mathrm{~mm}$, and the lengths of baffles into the bottom plate and paralleled to the inclined web are $15 \mathrm{~mm}$ and $25 \mathrm{~mm}$, respectively. In the latter condition, baffles are set with a $15 \mathrm{~mm}$ distance from the bottom plate and with a $15 \mathrm{~mm}$ depth into the central slotting. The baffle located in the central slotting is $45^{\circ}$ to the bottom plate. The layout is shown in Figure 6.

In order to compare the effects of different measures on VIV restraining, the test cases are arranged as follows.

Case 0 . The original girder (with the grating of $100 \%$ opening ratio, a web inclined angle of $109^{\circ}$, and no baffles).

Case $1.0 \%$ grating opening ratio.

Case 2. 20\% grating opening ratio.

Case 3. $40 \%$ grating opening ratio.

Case $4.60 \%$ grating opening ratio. 
TABLE 2: Primary parameters of sectional model.

\begin{tabular}{lcccc}
\hline Name & Unit & Value of real bridge & Similarity ratio & Model design value \\
\hline Equivalent mass $(m)$ & $\mathrm{kg} / \mathrm{m}$ & 40369.9 & $1 / 45^{2}$ & 19.94 \\
Equivalent mass moment $\left(J_{m}\right)$ & $\mathrm{Kg} \cdot \mathrm{m}^{2} / \mathrm{m}$ & 4302810 & $1 / 45^{4}$ & 1.05 \\
Basic frequency of vertical bending $\left(f_{b}\right)$ & $\mathrm{Hz}$ & 0.36 & $45 / 2.7$ & 6,030 \\
Basic frequency of torsion $\left(f_{t}\right)$ & $\mathrm{Hz}$ & 0.93 & $45 / 2.7$ & 15.42 \\
\hline
\end{tabular}

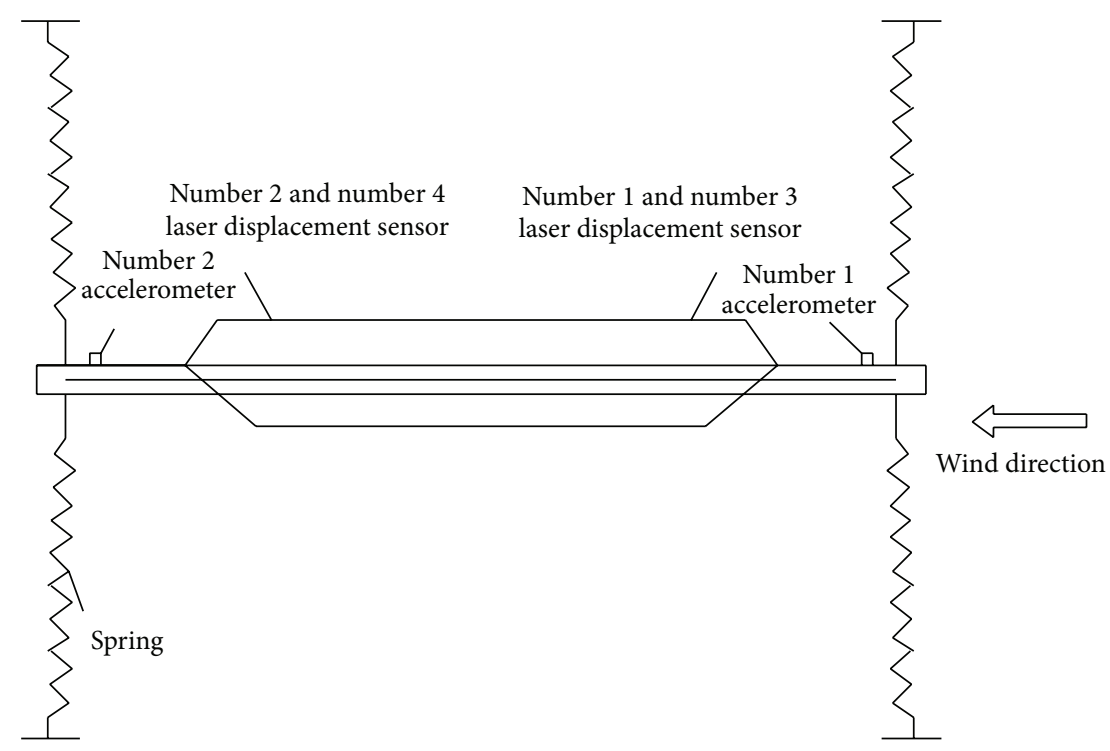

Figure 3: Layout of laser displacement sensors and laser acceleration sensors.

TABLE 3: Characteristics of the VIV of the bridge.

\begin{tabular}{lcc}
\hline $\begin{array}{l}\text { Wind attack } \\
\text { angle (deg.) }\end{array}$ & $\begin{array}{c}\text { Velocity lock-in region } \\
\text { Wind speed of actual bridge }(\mathrm{m} / \mathrm{s})\end{array}$ & $\begin{array}{c}\text { Amplitude } \\
\text { of VIV }(\mathrm{mm})\end{array}$ \\
\hline 3 & $8.37-11.47,21.7-31.31$ & 124.955, \\
& & 164.744 \\
0 & $8.99-11.47,21.70-25.42$ & 124.955, \\
& & 164.744 \\
-3 & $8.99-11.47,18.6-25.73$ & 114.093, \\
\end{tabular}

Case $5.80 \%$ grating opening ratio.

Case $6.119^{\circ}$ angle of inclined web.

Case $7.129^{\circ}$ angle of inclined web.

Case $8.139^{\circ}$ angle of inclined web.

Case 9. Side baffles.

Case 10. Central baffles.

\subsection{Test Results}

3.3.1. Grating. According to the wind tunnel test, the VIV characteristics of the girder with different opening ratios at different wind attack angles are shown in Figure 7.

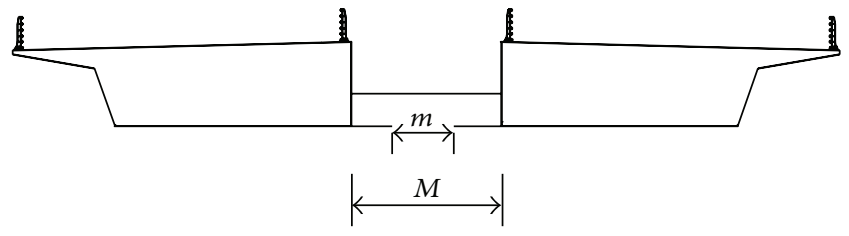

FIGURE 4: Diagram of the grating of the girders.

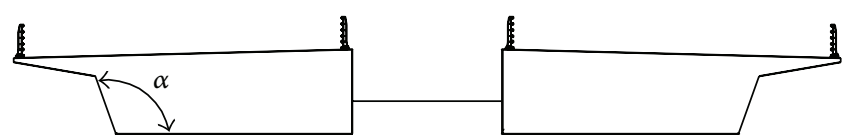

FIGURE 5: Diagram of the angle of inclined web.

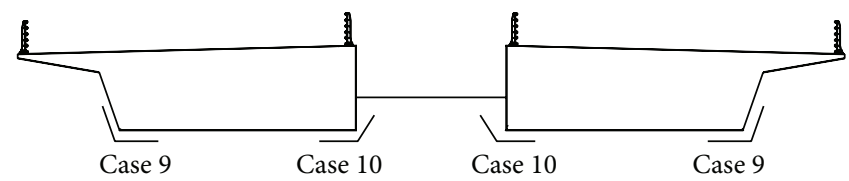

FIGURE 6: Arrangement diagram of baffles.

In Figure 7, when the wind attack angle is $0^{\circ}$, regardless of grating opening ratio, the bending VIV is restrained, but the characteristics of the torsional VIV are complicated. When the grating opening ratio is $20 \%$, the bending VIV is 


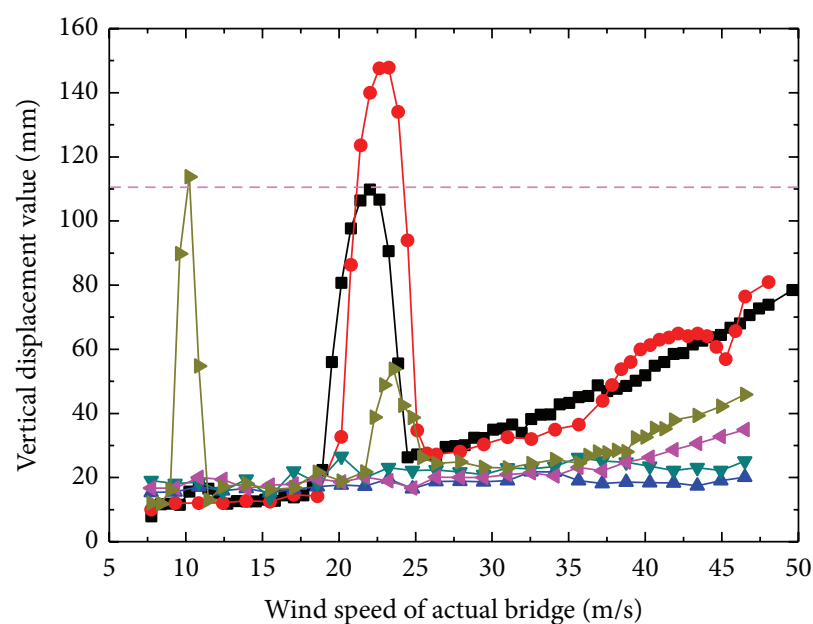

(a) VIV of the girders with grating of different opening ratios at wind attack angle of 0 deg.

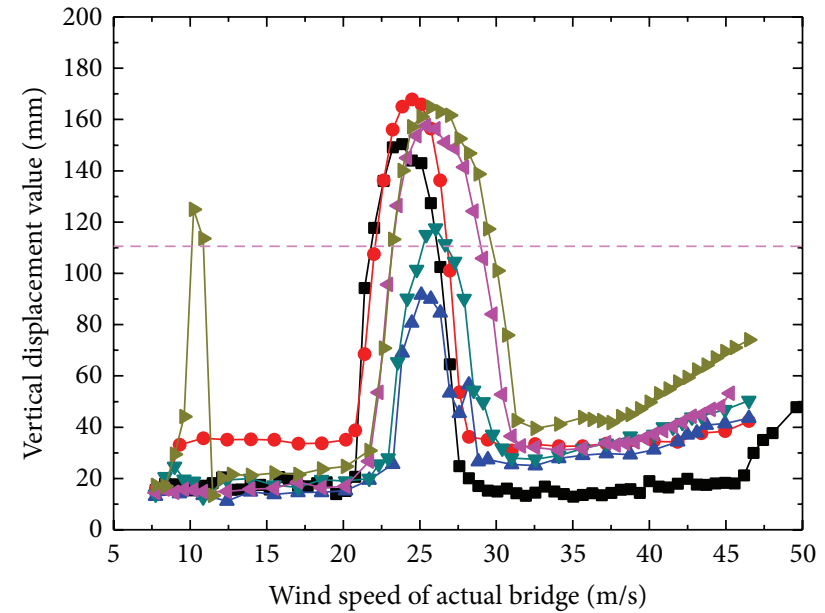

(b) VIV of the girders with grating of different opening ratios at wind attack angle of $3 \mathrm{deg}$.

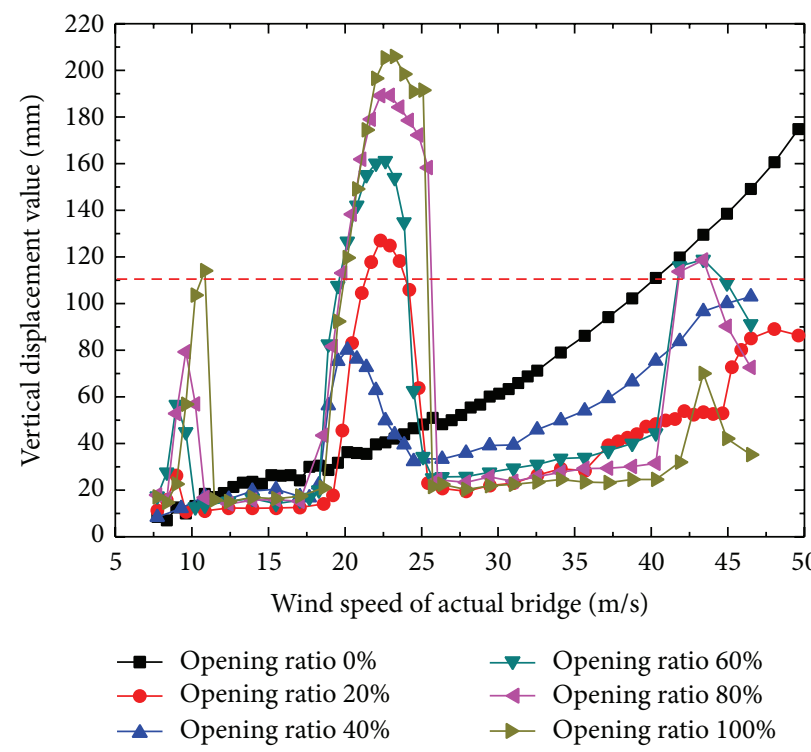

(c) VIV of the girders with grating of different opening ratios at wind attack angle of -3 deg.

FIGURE 7: VIV of the girders with grating of different opening ratios.

mitigated significantly. At the grating opening ratios of $40 \%$, $60 \%$, and $80 \%$, both of the bending and torsional VIV are all restrained significantly. At the wind attack angle of $-3^{\circ}$ and $+3^{\circ}$, when the grating opening ratio is $40 \%$, the bending VIV is mitigated, and the torsional VIV is effectively reduced. From the above, it is clear that the grating opening ratio of $40 \%$ is the best one. It indicates that there is an optimum opening ratio to restrain or mitigate the VIV.

3.3.2. Angle of Inclined Web. In Figure 8, for the bending VIV, whether the wind attack angle is $0^{\circ}, 3^{\circ}$, or $-3^{\circ}$, the amplitude is the smallest when the web inclined angle is $119^{\circ}$. As the angle increases, the amplitude of bending VIV increases, the region of lock-in wind velocity of the VIV becomes narrower, and the starting speed of the VIV decreases.
For the torsional VIV, when the angle of inclined web increases and the wind attack angle is $0^{\circ}, 3^{\circ}$, or $-3^{\circ}$, the beginning speed of the VIV will become lower, the lock-in region of the VIV narrower, and the amplitude of the VIV larger. Among them, when the web inclined angle is $119^{\circ}$ and the wind attack angle is $-3^{\circ}$, the VIV amplitude still cannot meet the requirement of Wind-Resistant Design Specification for Highway. When the web inclined angle is $129^{\circ}$, the VIV will be restrained significantly. Furthermore, when the web inclined angle is $139^{\circ}$, the VIV will even disappear.

Above all, increasing the angle of inclined web can restrain the torsional VIV effectively. The larger the web inclined angle is, the better the control effect becomes. However, for the bending VIV, there is an optimum angle at which the amplitude is the smallest. The amplitude of 


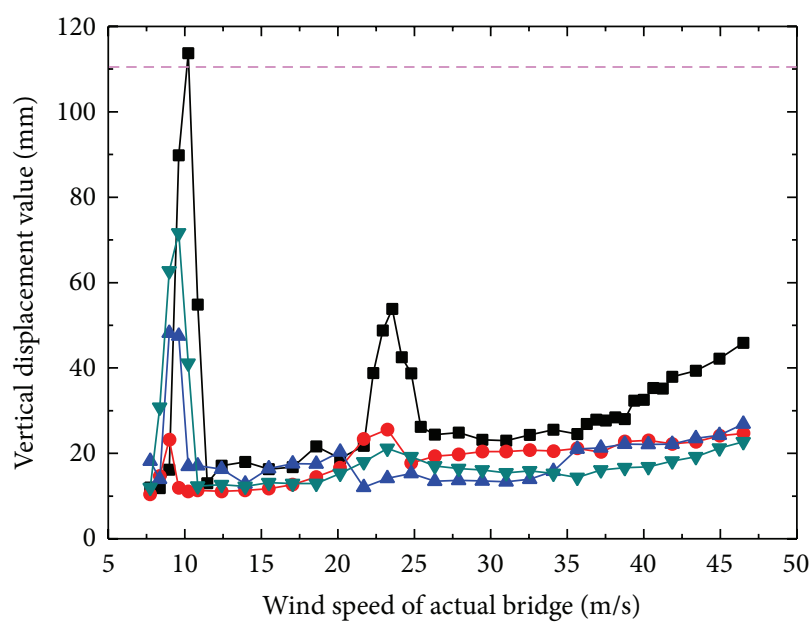

(a) VIV of the girders of different angles of incline web at wind attack angle of $0 \mathrm{deg}$.

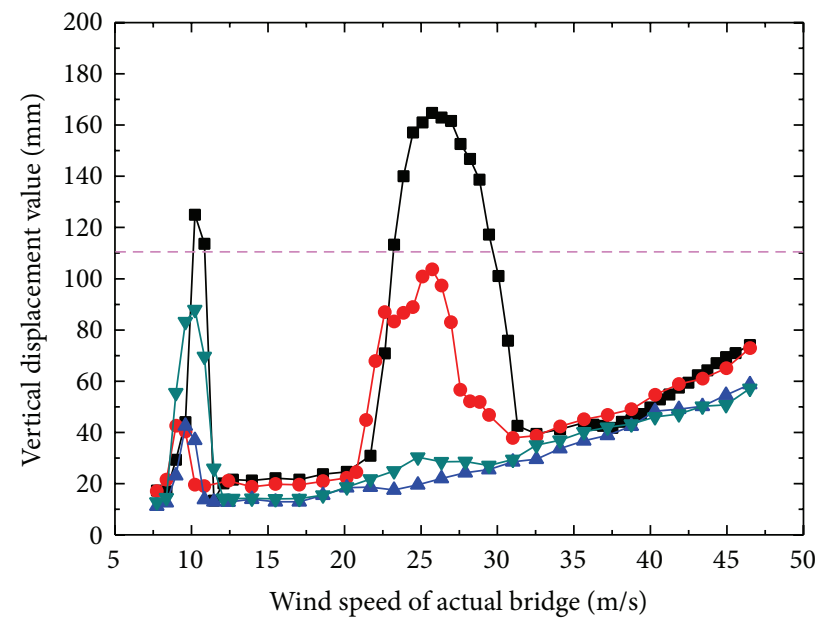

(b) VIV of the girders of different angles of incline web at wind attack angle of $3 \mathrm{deg}$.

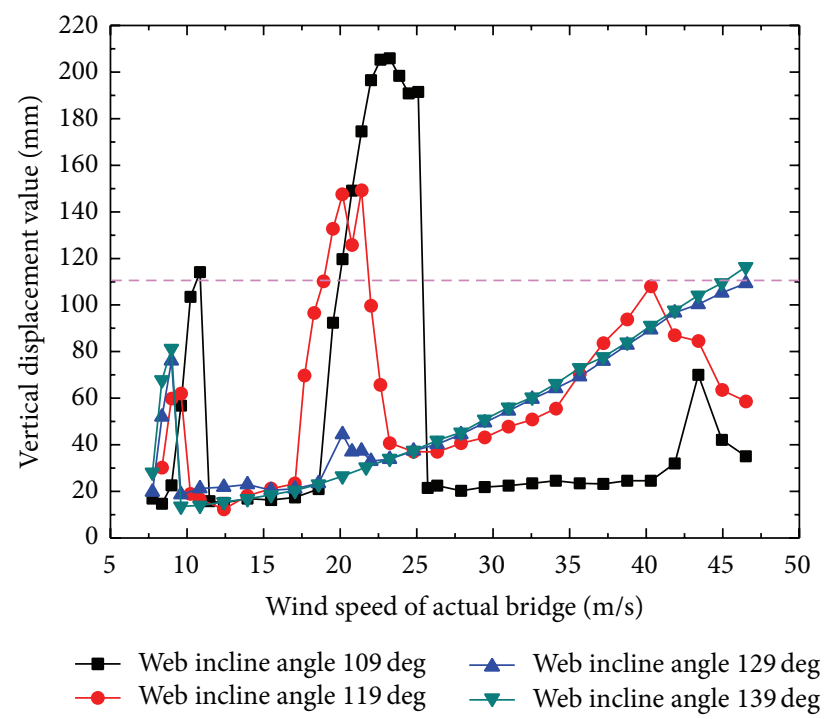

(c) VIV of the girders of different angles of incline web at wind attack angle of -3 deg.

Figure 8: VIV of the girders of different angles of inclined web.

the VIV increases with the web inclined angle that exceeds the optimum angle. Nowadays, most researchers are only concerned about the VIV at lower wind speed but neglect the VIV at higher wind speed. However, when the wind speed in the bridge location increases rapidly, the VIV at higher wind speed cannot be ignored.

3.3.3. Baffles. In Figure 9, the VIV will hardly happen when baffles are set on both sides of the inclined webs. When baffles are set in the middle of the central position of deck, the VIV will still occur and the lock-in wind speed region will hardly change. Although the amplitude of the bending VIV is much smaller, the amplitude of the torsional VIV is reduced insignificantly at $3^{\circ}$ and $-3^{\circ}$ wind attack angles. It is obvious that baffles on both sides of the inclined webs are more effective to restrain the VIV.

\section{Discussion}

4.1. General. In order to study the mechanisms of the VIV in different cases, the Computational Fluent Dynamics (CFD) technology is used to explain the mechanism of the VIV. Seen from the test results, the lock-in wind speeds of the bending VIV under different conditions are all close to $10 \mathrm{~m} / \mathrm{s}$. In the following CFD analysis, the wind speed is taken as $10 \mathrm{~m} / \mathrm{s}$, and the wind attack angle is $0^{\circ}$. Since the VIV of the bridge is in vertical direction, the vertical wind pressure on the main girder is used as an indicator of VIV evaluation.

4.2. CFD Analysis of Different Measures. Nowadays, most of the CFD analysis cases for the bridges focus on closed box section decks. This study tries to make use of CFD to study the mechanism of different aerodynamic measures on the separate pairs of box girders. 


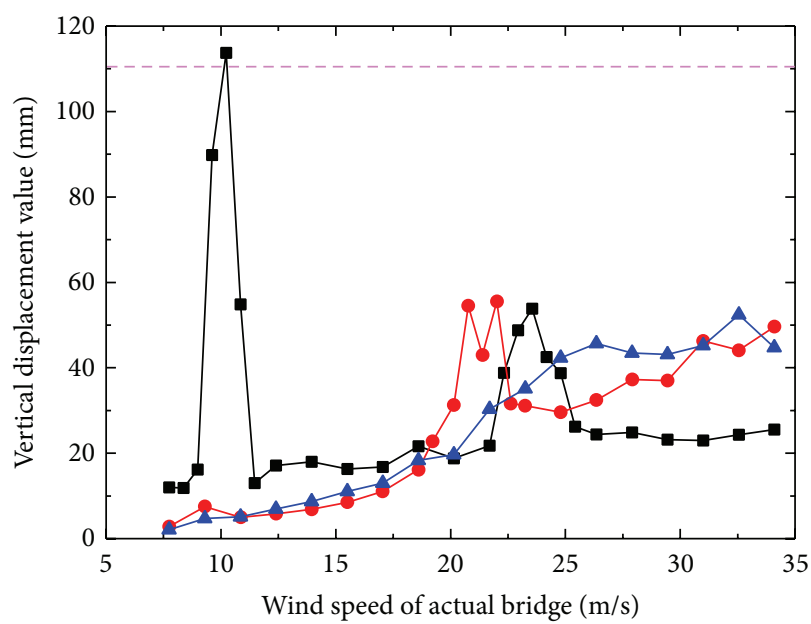

(a) VIV of the girders with baffles at wind attack angle of $0 \mathrm{deg}$.

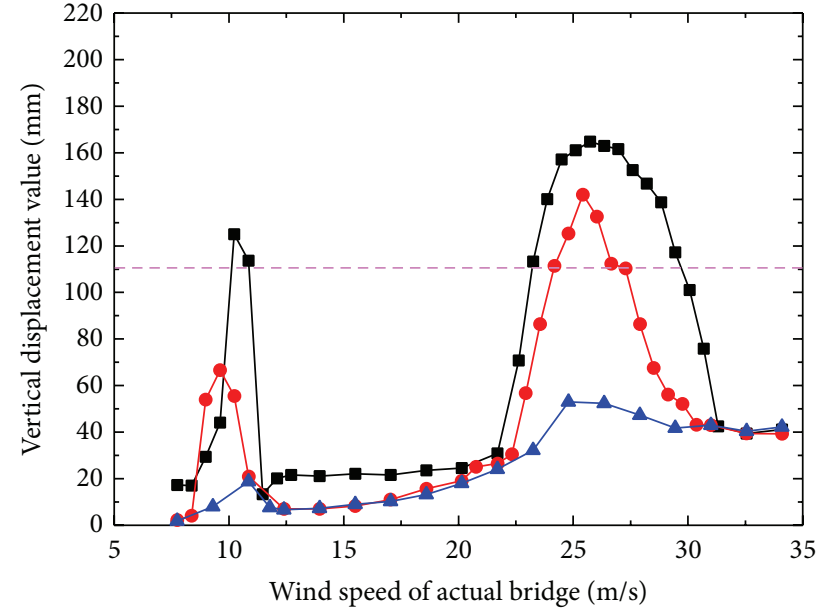

(b) VIV of the girders with baffles at wind attack angle of $3 \mathrm{deg}$.

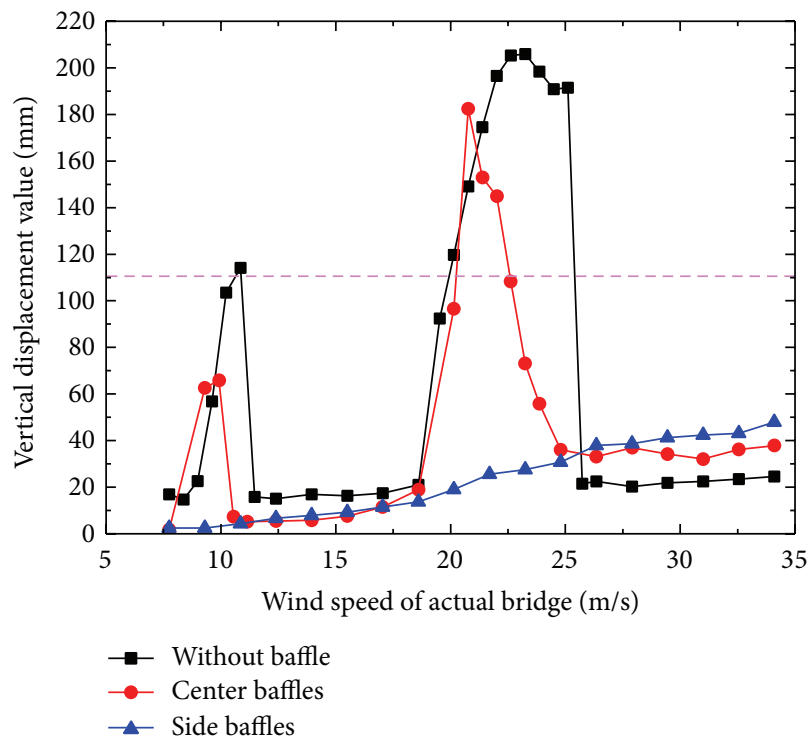

(c) VIV of the girders with baffles at wind attack angle of -3 deg.

FIGURE 9: VIV of the girders with baffles.

4.2.1. Grating. In Figure 10, the airflow around surfaces of the deck moves relatively slow when the opening ratio of the grating is $0 \%$ or $20 \%$, respectively. However, the airflow around the region which is far away from the girder moves at much higher speed. In this situation, the stationary airflow over the upper and lower surfaces of the girder can easily produce air pressure. Obviously, the low-speed airflow of the upper surface is much more than that of the lower surface, which leads to a big difference of air pressure. The big difference of air pressure will force the main girder to vibrate in vertical direction. When the opening ratio is $100 \%, 80 \%$, or $60 \%$, respectively, there is a great difference of air pressure distributions between upper and lower surfaces, which will lead to vertical vibration of the girder. When the opening ratio is $40 \%$, there is little difference of air pressures between the upper and lower surfaces of the deck, and the downstream wind speed far from the girder is smaller than that around the girder. This will make it hard for airflow to stay on the girder surface to induce a vertical air pressure difference.

4.2.2. Angle of Inclined Web. In Figure 11, when the wind speed is set at $10 \mathrm{~m} / \mathrm{s}$ and the web plate inclined angle is $109^{\circ}$, the difference of the wind speeds near the web is the largest, followed by those at the web plate inclined angles of $119^{\circ}$ and $129^{\circ}$. When the web plate inclined angle is $139^{\circ}$, the difference of the wind speeds around the girder is the smallest. This predicates that there is less stationary airflow around the girder and it is difficult to produce an air pressure which can lead to vertical vibration of the girder. In this case, once the vibration occurs, the amplitude may become larger due to 


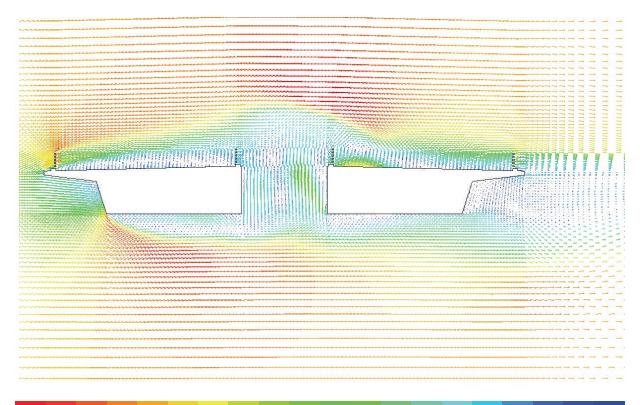

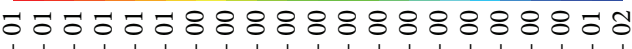
t + + + + + + + + + + + + + + + + + + 1 ஸั

Velocity vectors colored by velocity magnitude $(\mathrm{m} / \mathrm{s})$

(a) Flow field trace of the section with grating of $100 \%$ opening ratio

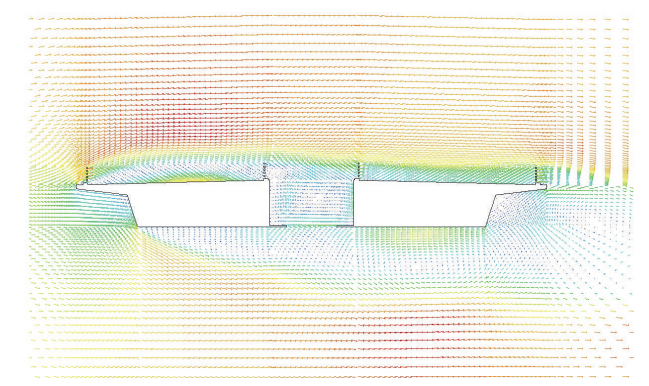

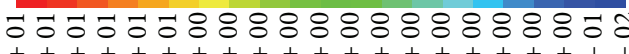

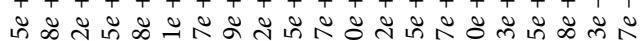

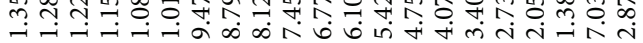

Velocity vectors colored by velocity magnitude $(\mathrm{m} / \mathrm{s})$

(c) Flow field trace of the section with grating of $60 \%$ opening ratio
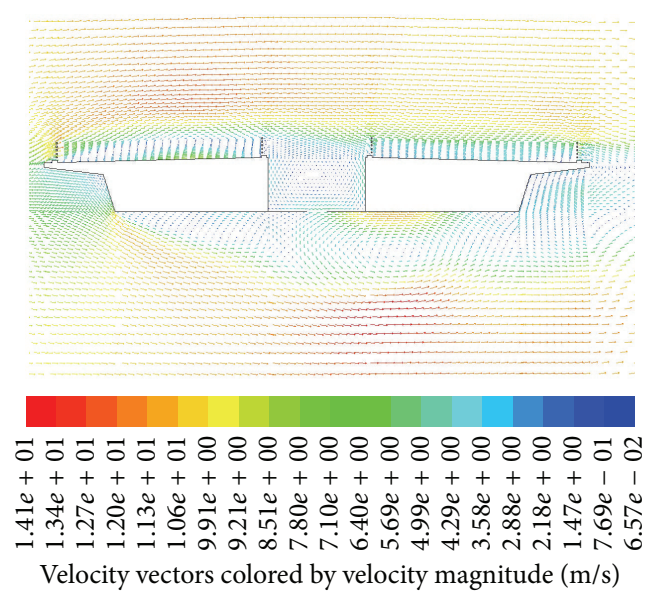

(e) Flow field trace of the section with grating of $20 \%$ opening ratio

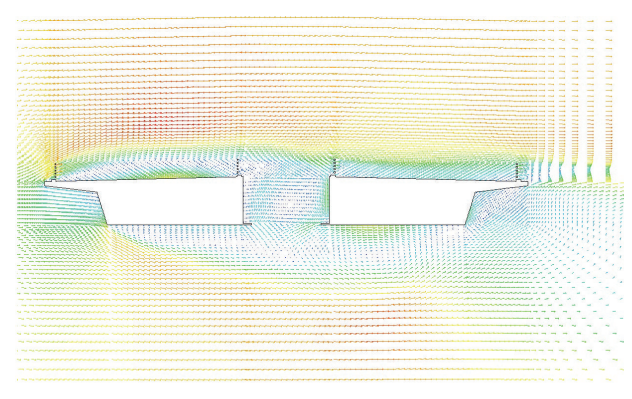

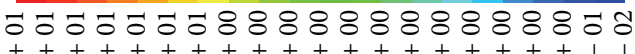

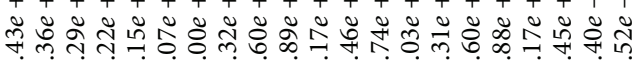

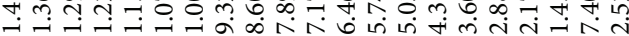

Velocity vectors colored by velocity magnitude $(\mathrm{m} / \mathrm{s})$

(b) Flow field trace of the section with grating of $80 \%$ opening ratio

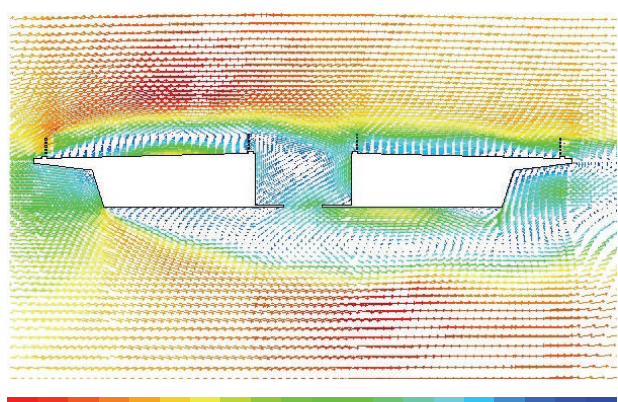

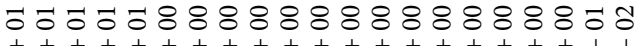
mँ

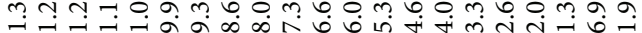

Velocity vectors colored by velocity magnitude $(\mathrm{m} / \mathrm{s})$

(d) Flow field trace of the section with grating of $40 \%$ opening ratio
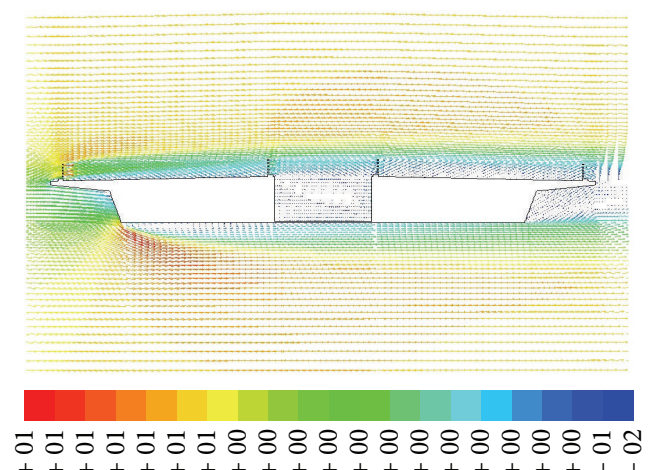
$+++++++++++++++++++1$

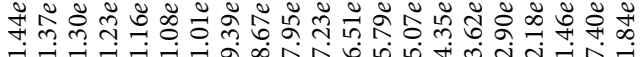

Velocity vectors colored by velocity magnitude $(\mathrm{m} / \mathrm{s})$

(f) Flow field trace of the section with grating of $0 \%$ opening ratio

Figure 10: Flow field trace of the section with grating of different opening ratios at wind attack angle of $0 \mathrm{deg}$. (10 m/s). 


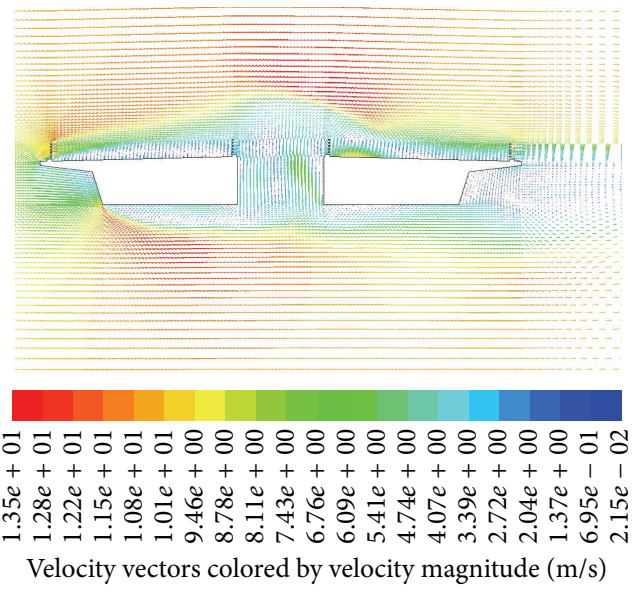

(a) Flow field trace of the section of 109 deg. angle of incline web

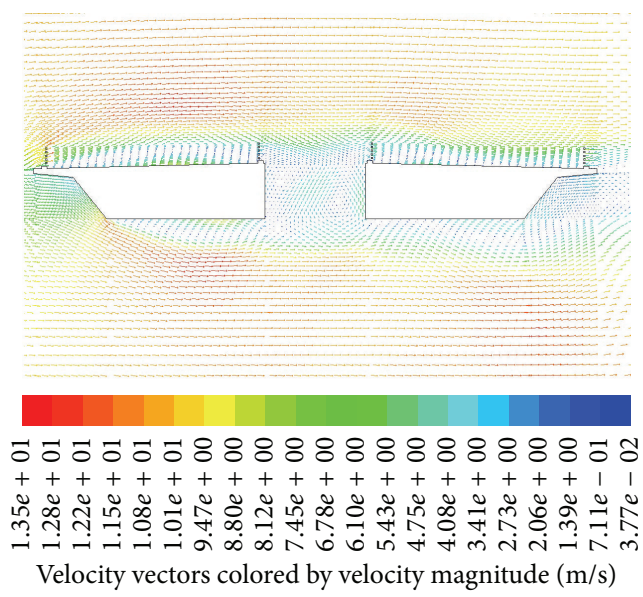

(c) Flow field trace of the section of 129 deg. angle of incline web
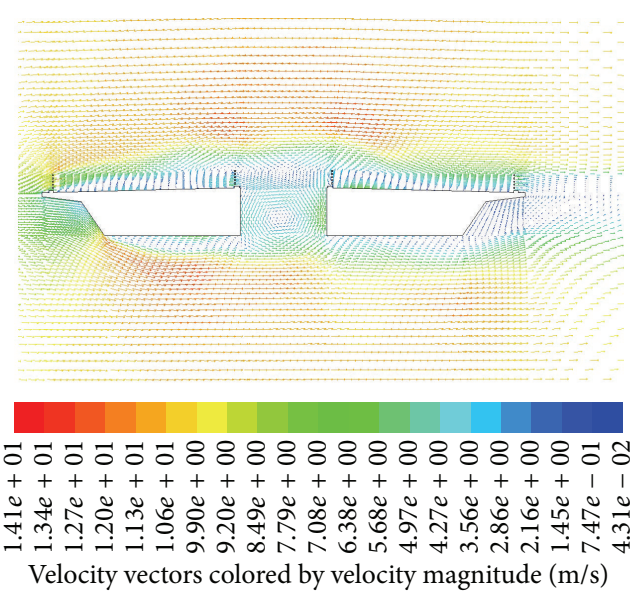

(b) Flow field trace of the section of $119 \mathrm{deg}$. angle of incline web

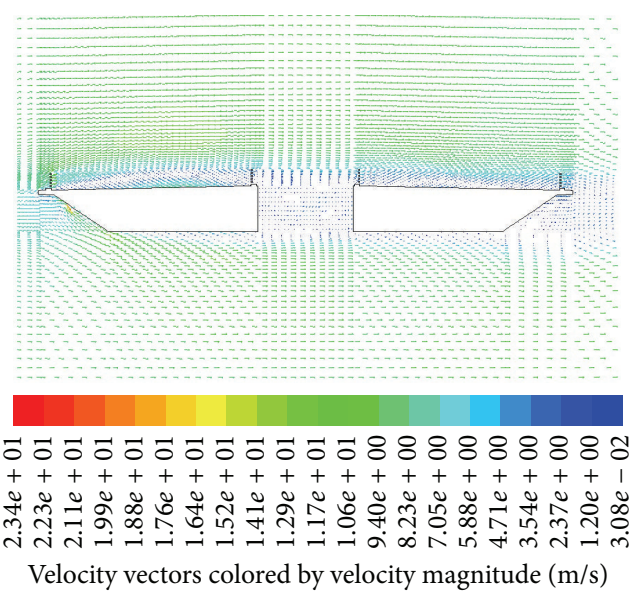

(d) Flow field trace of the section of 139 deg. angle of incline web

FIGURE 11: Flow field trace of the section of different angles of inclined web at wind attack angle of 0 deg. $(10 \mathrm{~m} / \mathrm{s})$.

little difference between air pressures around the girder. Then the airflow can stay more easily over the upper and lower surfaces of the girder, which will contribute to VIV.

4.2.3. Baffles. As shown in Figure 12, in the case of missing baffles, there is a lower wind speed between the web and bottom and a higher wind speed in the region far away from the girders, which will easily induce the vortex around the girder and lead to the occurrence of VIV. When baffles are arranged on both sides of the inclined webs at the time of low wind speed, the baffles will force the positive vortex near the inclined web downstream of the girder to move far away from the girder. The negative vortex above the positive vortex turns from a round shape into a slender oval shape and extends further due to the downstream migration of the positive vortex. By guiding the downstream airflow, the airflow does not separate at the front end of the girder but moves in the direction of baffle guidance. After passing through the gallery formed by the baffles, the airflow at the bottom of main girder will break up the wake flow vortex at a certain speed. When the airflow passes through the corner between the web and the bottom plate, the wind speed will increase obviously to weaken the effect of vortex aerodynamic forces so that the VIV will fade rapidly.

\section{Conclusion}

The VIV characteristics of separate pairs of box girders in cable-stayed bridges are discussed in this paper theoretically and experimentally. From the segmental model test in wind tunnel and by CFD analysis, the following results can be concluded: (1) the grating of different opening ratios can efficaciously control the VIV of the girder. There is an optimum opening ratio in the grating, by which the VIV can be controlled most effectively; (2) increasing the angle of inclined web can effectively restrain the torsional VIV of the girder. The larger the web inclined angle is, the better the control effect becomes. For the bending VIV of the bridge, there is an optimum angle where the amplitude is the smallest. The amplitude of the VIV increases with the web inclined angle that exceeds the optimum angle; (3) both central baffles and sides baffles are effective for the VIV 


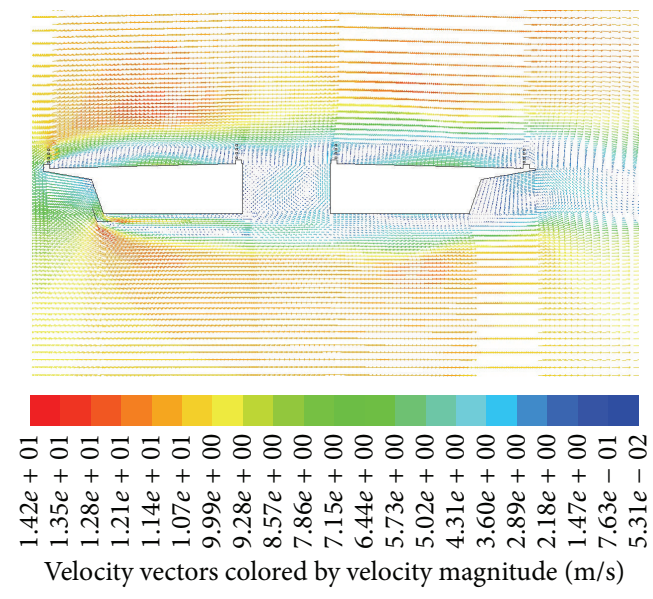

(a) Flow field trace of the section with sides baffles

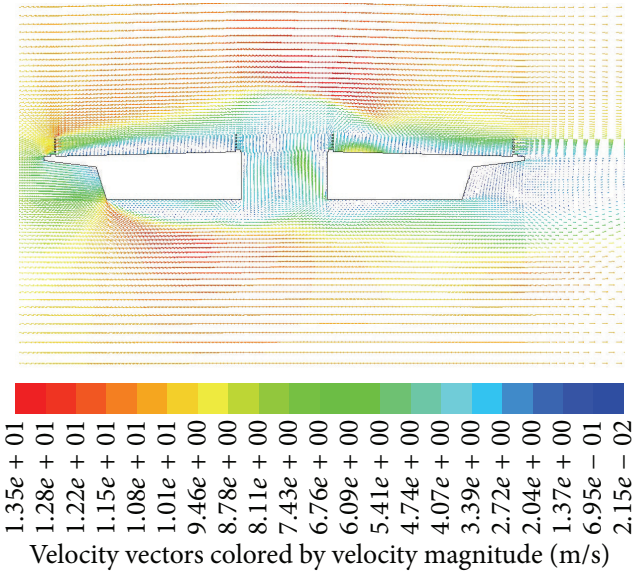

(b) Flow field trace of the section without baffles

FIGURE 12: Flow field trace of the section with baffles at wind attack angle of 0 deg. $(10 \mathrm{~m} / \mathrm{s})$.

control of the girder, especially for the girder with sides baffles; then the VIV of the girder hardly occurs.

\section{Conflict of Interests}

The authors declare that there is no conflict of interests regarding the publication of this paper.

\section{Acknowledgments}

This paper was funded by the Special Research Project of Shaanxi Education Department of China, under Grant no. 14jk1436. The authors thank Chang'an University Wind Tunnel Laboratory for their supply of experimental instruments and equipment and also are grateful to Professor J. Li for his constructive suggestions.

\section{References}

[1] V. Strouhal, "Ueber eine besondere Art der Tonerregung," Annalen der Physik, vol. 241, no. 10, pp. 216-251, 1878 (German).

[2] L. Rayleigh, Theory of Sound, Macmillan, London, UK, 2nd edition, 1896.

[3] K. H. Von and H. Rubach, "Ueber den mechanismus des flussigkeits-und luftwiderstandes," Physikalische Zeitschrift, vol. 13, pp. 49-59, 1912 (German).

[4] F. H. Abernathy and R. E. Kronauer, "The formation of vortex streets," Journal of Fluid Mechanics, vol. 13, no. 1, pp. 1-20, 1962.

[5] R. E. D. Bishop and A. Y. Hassan, "The lift and drag forces on a circular cylinder oscillating in a flowing fluid," Proceedings of the Royal Society, Series A: Mathematical, Physical and Engineering Sciences, vol. 277, no. 1368, pp. 51-75, 1964.

[6] T. Sarpkaya, "Vortex-induced oscillations," Journal of Applied Mechanics, vol. 46, no. 2, pp. 241-258, 1979.

[7] P. W. Bearman, "Vortex shedding from oscillating bluff bodies," Annual Review of Fluid Mechanics, vol. 16, no. 1, pp. 195-222, 1984.
[8] C. H. K. Williamson, "Vortex dynamics in the cylinder wake," Annual Review of Fluid Mechanics, vol. 28, no. 1, pp. 477-539, 1996.

[9] T. Sarpkaya, "A critical review of the intrinsic nature of VIV", Fluid Mechanics and its Applications, vol. 75, pp. 159-161, 2004.

[10] C. H. K. Williamson and R. Govardhan, "Vortex-induced vibrations," Annual Review of Fluid Mechanics, vol. 36, no. 1, pp. 413-455, 2004.

[11] F. Xu, W.-L. Chen, Y.-Q. Xiao, H. Li, and J.-P. Ou, "Numerical study on the suppression of the vortex-induced vibration of an elastically mounted cylinder by a traveling wave wall," Journal of Fluids and Structures, vol. 44, pp. 145-165, 2014.

[12] S. Komatsu and H. Kobayashi, "Vortex-induced oscillation of bluff cylinders," Journal of Wind Engineering and Industrial Aerodynamics, vol. 6, no. 3-4, pp. 335-362, 1980.

[13] N. Shiraishi and M. Matsumoto, "On classification of vortexinduced oscillation and its application for bridge structures," Journal of Wind Engineering and Industrial Aerodynamics, vol. 14, no. 1-3, pp. 419-430, 1983.

[14] M. Matsumoto, N. Shiraishi, H. Shirato, S. Stoyanoff, and T. Yagi, "Mechanism of, and turbulence effect on vortex-induced oscillations for bridge box girders," Journal of Wind Engineering and Industrial Aerodynamics, vol. 49, no. 1-3, pp. 467-476, 1993.

[15] G. L. Larose, S. V. Larsen, A. Larsen, M. Hui, and A. G. Jensen, "Sectional model experiments at high Reynolds number for the deck of a $1018 \mathrm{~m}$ span cable-stayed bridge," in Proceedings of the 11th International Conference on Wind Engineering, pp. 373-380, Lubbock, Tex, USA, 2003.

[16] J. S. Owen, A. M. Vann, J. P. Davies, and A. Blakeborough, “The prototype testing of Kessock Bridge: response to vortex shedding," Journal of Wind Engineering and Industrial Aerodynamics, vol. 60, no. 1-3, pp. 91-108, 1996.

[17] C. B. Ronaldo and S. P. Michèle, "Reduction of vortex-induced oscillations of Rio-Niterói bridge by dynamic control devices," Journal of Wind Engineering and Industrial Aerodynamics, vol. 84, no. 3, pp. 273-288, 2000.

[18] A. Fujiwara, H. Kataoka, and M. Ito, "Numerical simulation of flow field around an oscillating bridge using finite difference method," Journal of Wind Engineering and Industrial Aerodynamics, vol. 46-47, pp. 567-575, 1993. 
[19] T. Nomura, "Finite element analysis of vortex-induced vibrations of bluff cylinders," Journal of Wind Engineering and Industrial Aerodynamics, vol. 46-47, pp. 587-594, 1993.

[20] W. Zhang, Z. Wei, Y.-J. Yang, and Y. Ge, "Comparison and analysis of vortex induced vibration for twin-box bridge sections based on experiments in different reynolds numbers," Journal of Tongji University (Natural Science), vol. 36, no. 1, pp. 6-11, 2008.

[21] H. Li, S. Laima, J. Ou et al., "Investigation of vortex-induced vibration of a suspension bridge with two separated steel box girders based on field measurements," Engineering Structures, vol. 33, no. 6, pp. 1894-1907, 2011.

[22] H. Li, S.-J. Laima, Q.-Q. Zhang, N. Li, and Z. Liu, "Field monitoring and validation of vortex-induced vibrations of a long-span suspension bridge," Journal of Wind Engineering and Industrial Aerodynamics, vol. 124, pp. 54-67, 2014.

[23] A. M. Marra, C. Mannini, and G. Bartoli, "Van der Pol-type equation for modeling vortex-induced oscillations of bridge decks," Journal of Wind Engineering and Industrial Aerodynamics, vol. 99, no. 6-7, pp. 776-785, 2011.

[24] A. Patil, S.-M. Jung, S.-B. Lee, and S.-D. Kwon, "Mitigation of vortex-induced vibrations in bridges under conflicting objectives," Journal of Wind Engineering and Industrial Aerodynamics, vol. 99, no. 12, pp. 1243-1252, 2011.

[25] J.-W. Seo, H.-K. Kim, J. Park, K.-T. Kim, and G.-N. Kim, "Interference effect on vortex-induced vibration in a parallel twin cable-stayed bridge," Journal of Wind Engineering and Industrial Aerodynamics, vol. 116, pp. 7-20, 2013.

[26] L.-D. Zhu, X.-L. Meng, and Z.-S. Guo, "Nonlinear mathematical model of vortex-induced vertical force on a flat closedbox bridge deck," Journal of Wind Engineering and Industrial Aerodynamics, vol. 122, pp. 69-82, 2013.

[27] S.-J. Kim, H.-K. Kim, R. Calmer, J. Park, G. S. Kim, and D. K. Lee, "Operational field monitoring of interactive vortexinduced vibrations between two parallel cable-stayed bridges," Journal of Wind Engineering and Industrial Aerodynamics, vol. 123, pp. 143-154, 2013.

[28] G. Morgenthal, A. Sánchez Corriols, and B. Bendig, "A GPUaccelerated pseudo-3D vortex method for aerodynamic analysis," Journal of Wind Engineering and Industrial Aerodynamics, vol. 125, pp. 69-80, 2014.

[29] Y.-X. Yang, Y.-J. Ge, and H.-F. Xiang, "Flutter control effect and mechanism of central-slotting for long-span bridges," China Civil Engineering Journal, vol. 39, no. 7, pp. 74-80, 2006.

[30] L.-Y. Li and Y.-J. Ge, "Experiments of vortex control for centralslotting on long-span bridges," Journal of Huazhong University of Science and Technology, vol. 36, no. 12, pp. 112-115, 2008. 

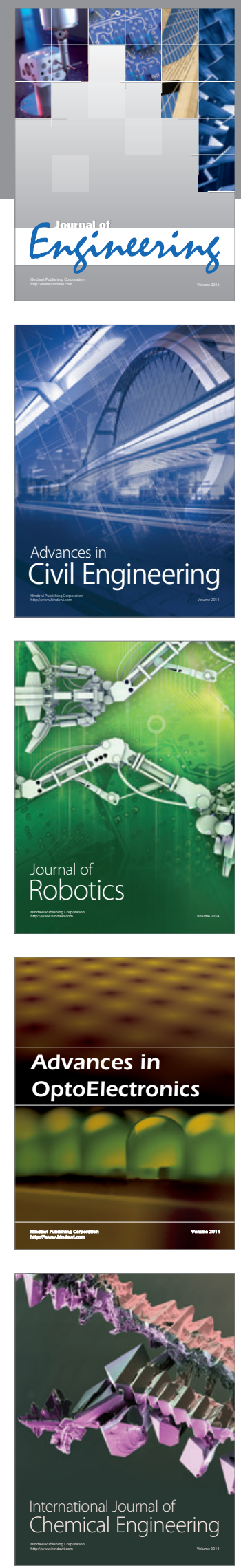

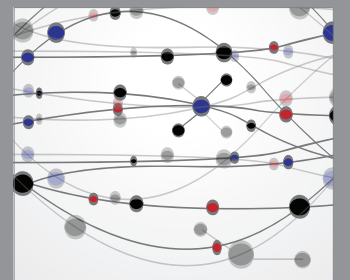

The Scientific World Journal
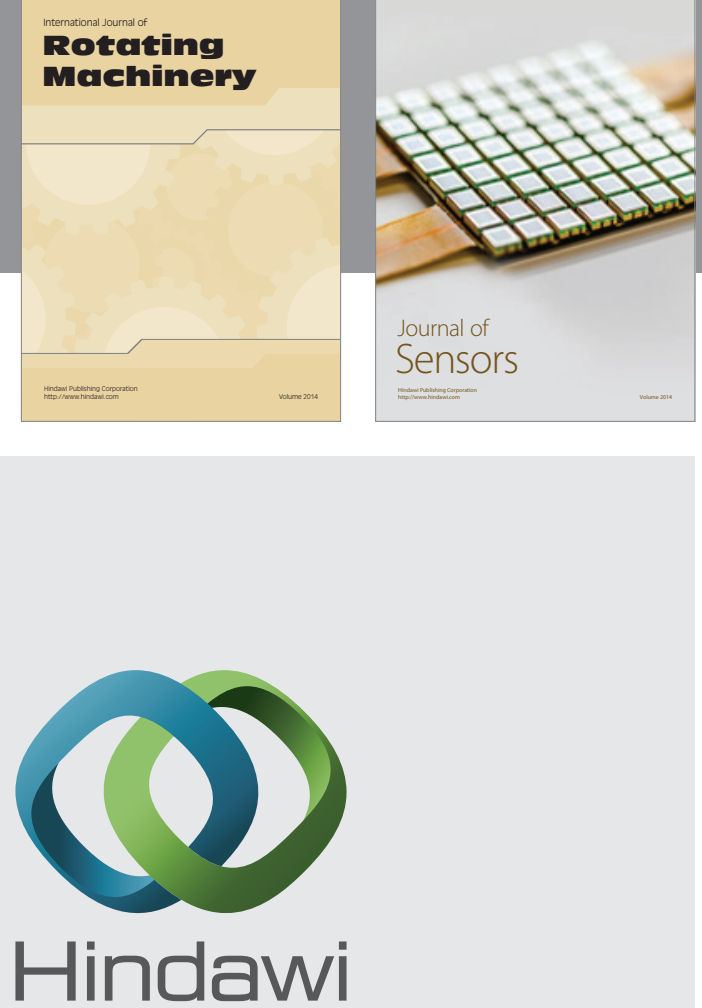

Submit your manuscripts at http://www.hindawi.com
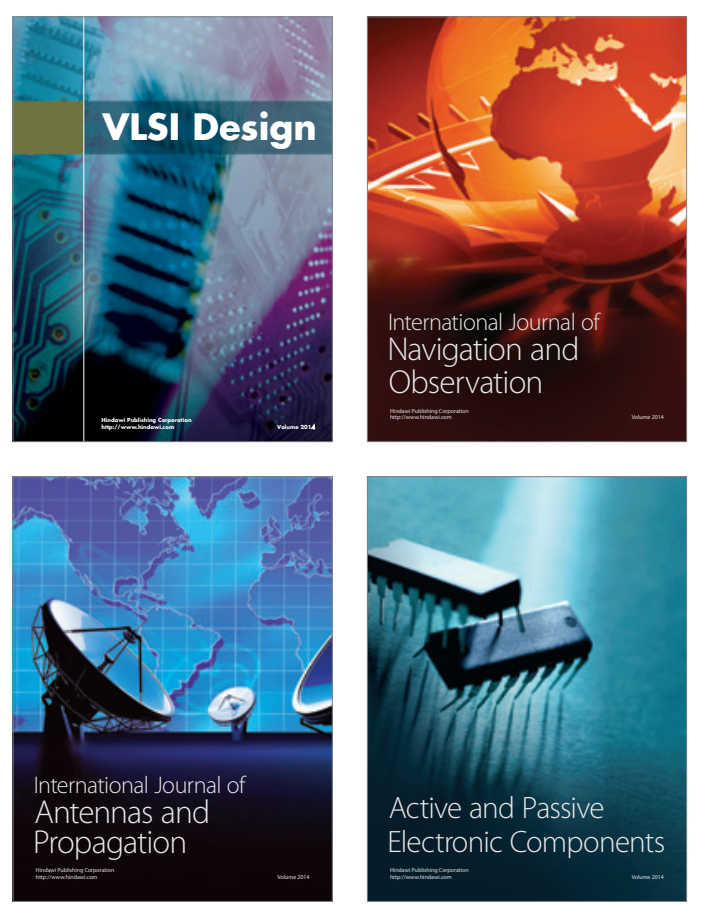
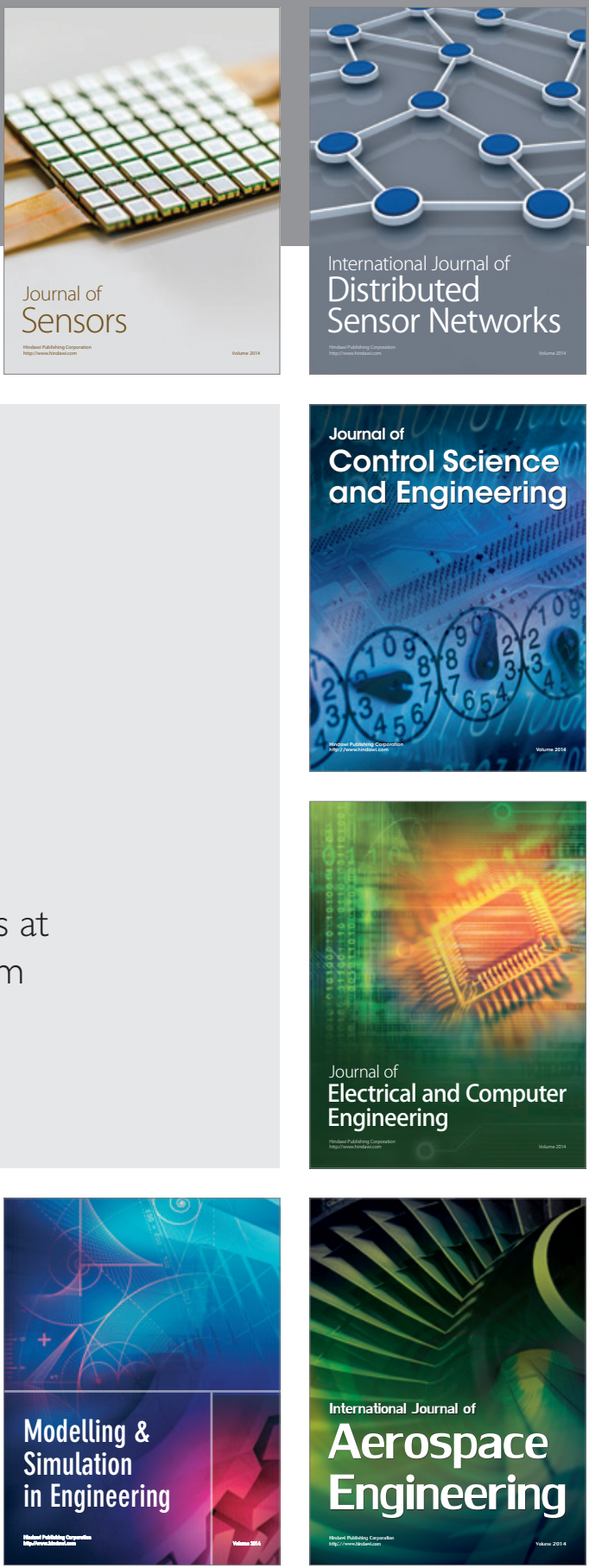

Journal of

Control Science

and Engineering
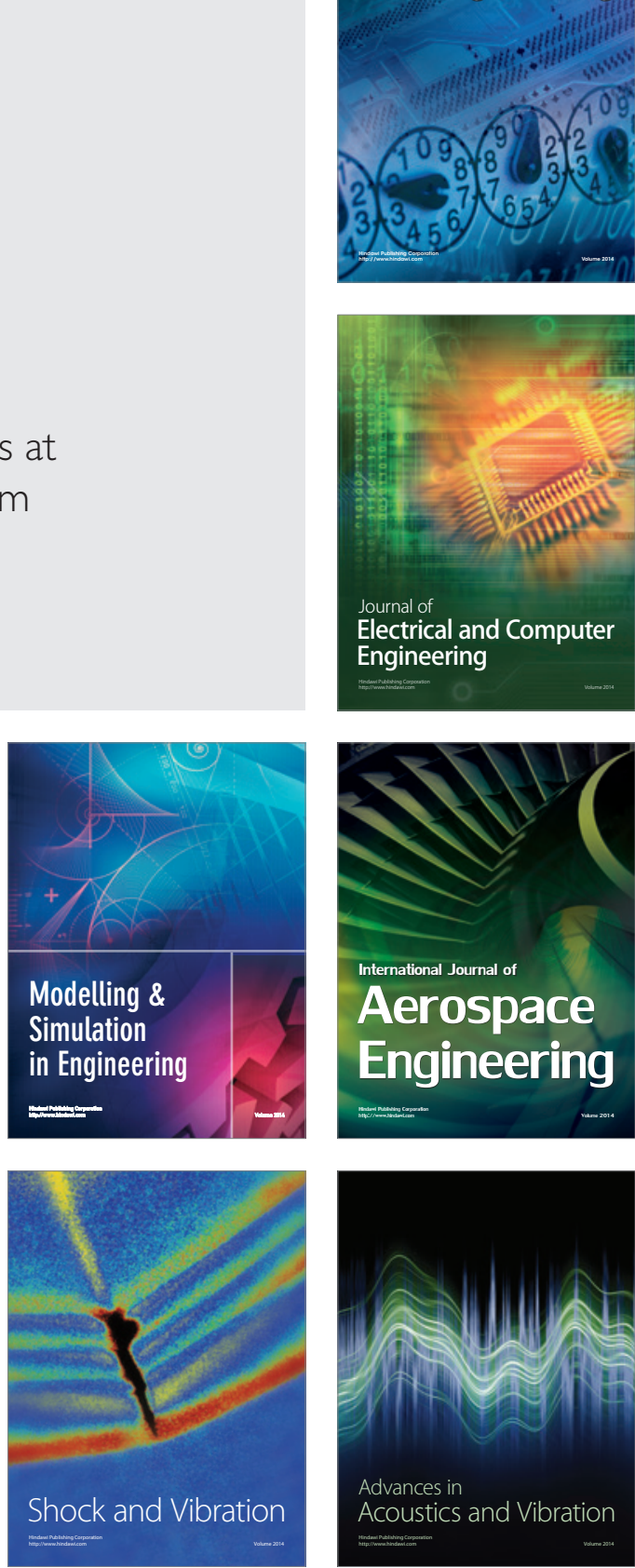